American Journal of Pharmacology and Toxicology 3 (1): 72-79, 2008

ISSN 1557-4962

(C) 2008 Science Publications

\title{
Behavioral, Physiological and Biochemical Hormetic Responses to the Autoxidizable Dye Methylene Blue
}

\author{
Aleksandra K. Bruchey and F. Gonzalez-Lima \\ Departments of Psychology, Pharmacology and Toxicology, \\ University of Texas at Austin, Austin, Texas 78712
}

\begin{abstract}
The goals of this review were to identify methylene blue (MB) as a compound that follows hormetic behavior for a wide range of effects and to address the question of what is unique about MB that could account for its wide applicability and hormetic behavior as a drug. The MB hormetic doseresponse relationship is exemplified by an increase in various behavioral, physiological and biochemical responses with increasing dose, followed by a decrease in the same responses with an even higher dose, until the responses are equal to control responses. With MB doses increasing beyond the hormetic zone, the responses decrease even further, until they are below the control responses. At doses spanning its hormetic zone, MB can increase select responses until they are 130-160\% of control. For example, low doses of MB produce maximum behavioral and biochemical responses with averages of approximately $140 \%$ of control. As MB dose is raised outside the hormetic zone the response decreases below the control response, as exemplified by MB's ability to increase cytochrome oxidase activity at intermediate doses, while decreasing cytochrome oxidase activity at higher doses. It is proposed that MB's autoxidizable chemical property may be responsible for its unique biological action as both a metabolic energy enhancer and antioxidant that is frequently characterized by hormetic dose-response relationships.
\end{abstract}

Key words: Memory, cytochrome oxidase, redox, hormesis, biological stress, neuroprotection

\section{INTRODUCTION}

Methylene blue (MB) is a remarkable compound in the history of pharmacology and chemotherapeutics. MB was the first phenothiazine compound developed and it has active biological properties which have been under investigation for over 120 years. MB was first prepared by Caro in 1876 as an aniline dye that became the first synthetic chemical tested in human patients, which Ehrlich demonstrated in 1891 as effective in malaria treatment ${ }^{[1]}$. The early works of Ehrlich lead to a great interest in the use of $\mathrm{MB}$ for numerous therapeutic applications, from microbiology to psychiatry. For example, MB is a therapeutic dye with antimicrobial activity, supravital staining and diagnostic histopathological uses, blood staining activity, medicinal photosensitiser action, cancer chemotherapeutic uses and psychoactive uses in dementia and psychosis ${ }^{[1-5]}$. Currently, some of the most important clinical uses of MB include the therapy of methemoglobinemia, septic shock, encephalopathy and ischemia $^{[1,6,7]}$.

MB was also the lead compound for successful synthesis of pharmacotherapeutic derivatives such as the antimalarial agents quinacrine and chloroquine, the phenothiazine antihistamines such as promethazine and the first antipsychotic drugs such as chlorpromazine ${ }^{[1]}$. The molecular structure of MB and its derivatives are characterized by a thiazine ring system or chromophore. This ring system is oxidized (aromatic) in MB while it is reduced (non-aromatic) in some of its derivatives such as chlorpromazine. MB derivatives of the oxidized ring type spearheaded the use of synthetic dyes in the industrial revolution, while $\mathrm{MB}$ derivatives of the reduced phenothiazine type brought about the birth of psychopharmacology and a revolution in the treatment of psychiatric patients. More recent research on MB's neurobiological and behavioral actions suggests that MB has powerful metabolic enhancing and antioxidant effects that facilitate memory ${ }^{[8-11]}$ and promote neuroprotection $^{[12]}$. In this wide range of effects, MB appears to follow hormetic dose-response relationships. Therefore, in this review we addressed the question of what is unique about $\mathrm{MB}$ that could account for its wide applicability and hormetic behavior as a drug.

Corresponding Author: F. Gonzalez-Lima, University Station A8000, University of Texas at Austin, Austin, TX $78712-0187$ Tel: (512) 471-5895 Fax: (512) 471-4728 


\section{MB'S AUTOXIDIZABLE MECHANISM OF ACTION}

A key chemical property of $\mathrm{MB}$ is that it is an autoxidizable dye (Fig. 1). That is, MB is a reducible dye with a reduction-oxidation capacity for electron cycling. MB will be reduced by accepting electrons from a reduced electron transport donor and it will in turn transfer electrons to oxygen to form water. Therefore, MB's autoxidizable property provides a chemical mechanism for electron transfer to oxygen, but $\mathrm{MB}$ does not gain any stoichiometric or net reduction. This autoxidizing property of MB may be responsible for various hormetic dose-response relationships ${ }^{[13]}$ which can be observed for the effects of $\mathrm{MB}$ at the behavioral, physiological and biochemical levels. In particular, the sequence of reductionoxidation events of $\mathrm{MB}$ in the electron transport chain in the mitochondria (Fig. 2) could explain why responses to $\mathrm{MB}$ are often characterized by nonlinear dose-response curves, where at low doses the response is opposite to that of higher doses, while the intermediate doses have little or no effect on the response variable.

MB can autoxidize both in vitro and in vivo. In its oxidized form, MB is blue in color and readily reduced by many living cells ${ }^{[14]}$. In order for MB to enter the cytosol, it is reduced at the exofacial cell surface into its colorless lipophilic form, leuko MB $\left(\mathrm{MBH}_{2}\right)^{[15]}$. Once inside the cell, this reduced $\mathrm{MBH}_{2}$ can be re-oxidized to $\mathrm{MB}$, which is trapped in the cell ${ }^{[16]}$. At low concentrations in vivo there is an equilibrium between $\mathrm{MB}$ and $\mathrm{MBH}_{2}$, in such a way that they form a reversible reduction-oxidation system. Through this mechanism MB can function as an electron cycler (donor/acceptor) and scavenger of free radicals, which has the potential to affect a wide variety of physiological responses. However, at high concentrations this equilibrium is impaired and MB can lead to oxidative stress at the cellular level ${ }^{[8]}$. Inside mitochondria, MB's electron cycling system may form the basis for its combined metabolic energy enhancing effect and antioxidant effect as scavenger of reactive oxygen species formed during cellular respiration.

In the mitochondria-containing cells, $\mathrm{MB}$ enters this organelle, most likely in its reduced $\mathrm{MBH}_{2}$ form, only to be oxidized again by heme proteins such as cytochrome $\mathrm{c}$ and cytochrome $\mathrm{c}$ oxidase ${ }^{[17]}$. However, MB can also be reduced by NADH-dehydrogenase of complex I of the mitochondrial electron transport chain, entering the oxidation-reduction cycle which can substitute electrons normally derived from oxygen and thus drive the electron transport chain energy

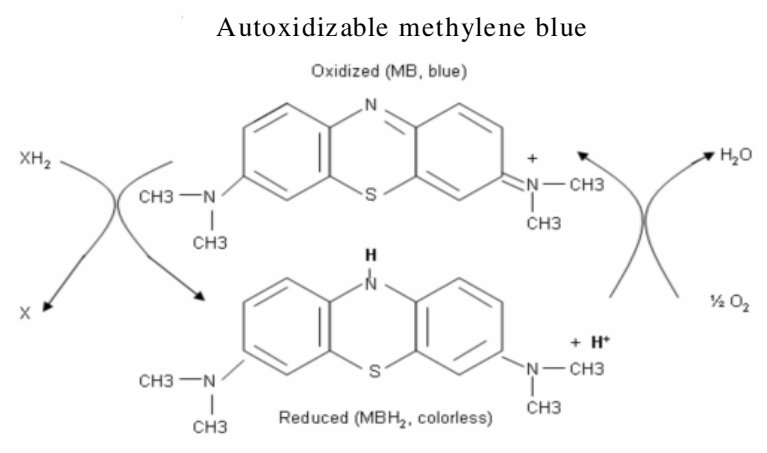

(a)

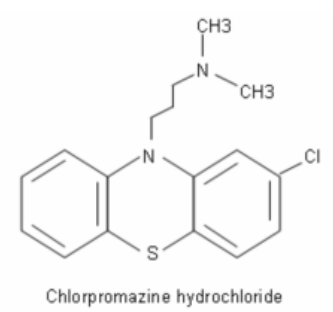

(b)

Fig. 1: Autoxidizable dye methylene blue. a) In its oxidized form methylene blue can accept electrons from an electron donor. In its reduced form, leukomethylene blue $\left(\mathrm{MBH}_{2}\right)$ is colorless, acts as an electron donor, and it can transfer electrons to oxygen to form water. Thus methylene blue is capable of autoxidizing. At low concentrations in vivo methylene blue and leukomethylene blue are at an equilibrium, so that they form a reversible reduction-oxidation system. This autoxidazing property provides a mechanisms for electron transfer to oxygen, and may be responsible for various hormetic doseresponse effects of methylene blue at the biochemical, physiological and behavioral levels. b) Chlorpromazine hydrochloride is a methylene blue derivative which shares a common phenothiazine ring system, as well as certain hormetic effects, with methylene blue. However, unlike methylene blue chlorpromazine hydrocholoride has a reduced (non-aromatic) ring system, and is not capable of autoxidizing. Therefore its applications are more circumscribed than the numerous therapeutic uses of methylene blue

production at lower ranges of $\mathrm{MB}$ doses. However, at higher doses, MB can take electrons away from the electron transport chain complexes, thus decreasing activity of these complexes and subsequent ATP 


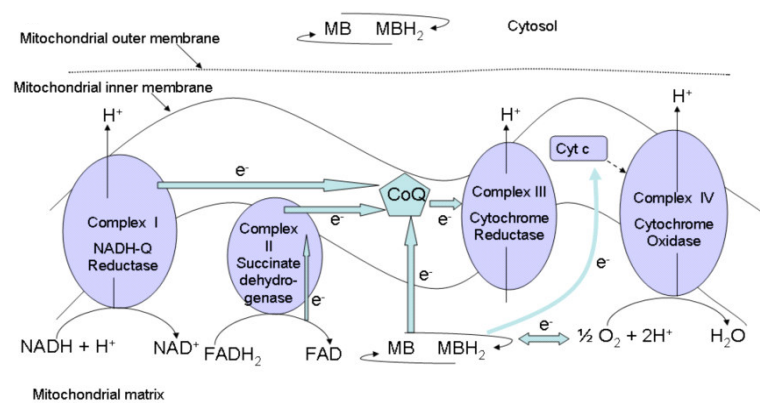

Fig. 2: Methylene blue can act as an artificial electron donor to the electron transport chain complexes of the mitochondria. Embedded in the inner mitochondrial membrane are several protein complexes capable of shuttling electrons and pumping protons against a concentration gradient into the intermembrane space, thus generating the proton gradient (energy) required for the ATP synthesis. These electron transport chain complexes can receive electrons from reduced cosubstrates such as NADH and $\mathrm{FADH}_{2}$ and transfer them to oxygen. Coenzyme Q is shared by complexes I, II and III, while cytochrome $\mathrm{c}$ is shared by complexes III and IV. Reduced methylene blue can donate electrons to coenzyme $\mathrm{Q}$ and possibly to the cytochrome $\mathrm{c}$, thus increasing cytochrome oxidase (complex IV) activity. In addition, at low doses methylene blue can also enter a reversible oxidation and reduction cycle and interact with oxygen to form water, which would decrease the superoxide radicals produced during the process of oxidative phosporylation. This way, methylene blue can act as an antioxidant inside the mitochondria where most of the oxygen reactive species are formed. At higher doses, methylene blue can take electrons away from the electron transport chain complexes, thereby decreasing activity of these complexes

production. An example of such hormetic doseresponse of $\mathrm{MB}$ is exemplified by MB's effect on cytochrome oxidase activity.

\section{HORMETIC MB RESPONSE ON MITOCHONDRIAL ELECTRON TRANSPORT CHAIN ENZYMATIC ACTIVITY}

A dose-response relationship illustrating the quantitative features of hormesis has been proposed by Calabrese and colleagues (2007). According to this

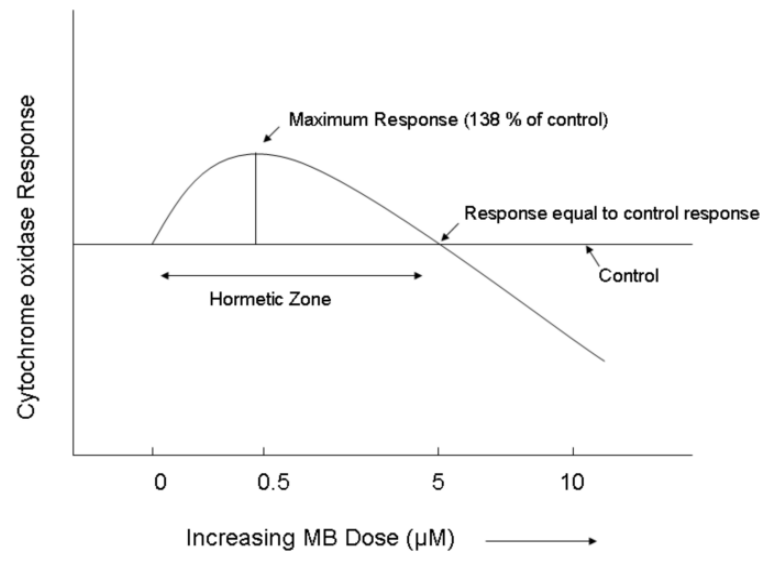

Fig. 3: Hormetic effects of methylene blue on brain cytochrome oxidase activity ${ }^{[8]}$. This is an example of in vitro hormetic dose-response relationships of methylene blue on a biochemical measure. Cytochrome oxidase is a terminal enzyme in the electron transport chain of the mitochondria, and as such acts on its substrate, cytochrome $\mathrm{c}$ in order to provide energy for ATP synthase. At low doses methylene blue can act as an electron donor and increase the amount of the reduced cytochrome c, thus elevating cytochrome oxidase activity, as measured spectrophotometrically. Maximum increase of $138 \%$ of control was achieved at 0.5 $\mu \mathrm{M}$ methylene blue dose, while a $5 \mu \mathrm{M}$ dose did not differ from control. When $10 \mu \mathrm{M}$ methylene blue was added to the rat brain homogenates, the cytochrome oxidase activity decreased bellow the baseline response, following principles of hormetic dose-response relationships outlined by Calabrese et al. ${ }^{[13]}$

hormetic dose-response framework, an agent (e.g., a chemical compound) exerts its maximum response of $130-160 \%$ of control within the middle of its hormetic zone. Therefore, with increasing doses, first there is an increase in the response, followed by a decrease in the same response, until the response is equal to control response. With doses increasing beyond the hormetic zone, the response decreases even further, until it is below the control response. As an example of hormesis, Calabrese et al. ${ }^{[13]}$ depict dose-time-response concerning the effects of chlorpromazine on neutral red uptake of mouse neuroblastoma cells. It is interesting to recall that chlorpromazine was originally derived from MB and that these two compounds have rather similar chemical structure with a common phenothiazine ring system (Figs. 1 and 3). 
Am. J. Pharm. \& Toxicol., 3 (1): 72-79, 2008

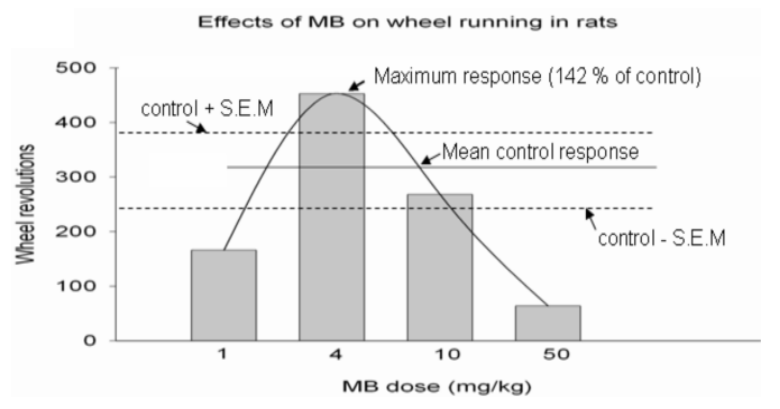

Fig. 4: Hormetic effects of methylene blue on spontaneous locomotor activity ${ }^{[10]}$. This is an example of in vivo hormetic dose-response relationships of methylene blue on a behavioral measure. Rats injected intraperitoneally with increasing doses of methylene blue were subjected to a running wheel test to examine general locomotor activity. The maximum wheel-running response (average 142\% of control) was observed for the intermediate $4 \mathrm{mg} \mathrm{kg}{ }^{-1}$ dose, while lower $(1 \mathrm{mg} / \mathrm{kg})$ and higher $\left(10 \mathrm{mg} \mathrm{kg}^{-1}\right)$ methylene blue doses did not differ from the baseline. Even higher doses ( $\geq 50 \mathrm{mg} \mathrm{kg}^{-1}$ ) decreased the wheel-running response below control levels. Therefore, methylene blue exerts hormetic dose-response effects on general locomotor activity in rats, with a hormetic zone between doses of $1 \mathrm{mg} \mathrm{kg}^{-1}$ and $10 \mathrm{mg} \mathrm{kg}^{-1}$

We investigated effects of $\mathrm{MB}$ on brain cytochrome oxidase activity in vitro using spectrophotometry and found a hormetic zone for MB's effect on this mitochondrial enzyme. Cytochrome oxidase is a terminal enzyme in the electron transport chain complex and as such is a rate-limiting enzyme for the production of $\mathrm{ATP}^{[18]}$. Cytochrome oxidase has an iron center and is thus in a position to bind and oxidize $\mathrm{MBH}_{2}$ when $\mathrm{MBH}_{2}$ is present at low doses. As shown in Fig.3, when $\mathrm{MB}$ was administered to rat brain homogenates a maximum cytochrome oxidase activity increase ( $138 \%$ of control) was achieved with a $0.5 \mu \mathrm{M}$ $\mathrm{MB}$ dose, while at $5 \mu \mathrm{M} \mathrm{MB}$ the cytochrome oxidase activity returned to control level ${ }^{[8]}$. As the dose of MB was increased, the cytochrome oxidase activity fell bellow the baseline response, suggesting that at $10 \mu \mathrm{M}$ dose, MB was taking electrons away from the electron transport chain complexes of the mitochondria. This may be because at low concentrations, $\mathrm{MB}$ is at an equilibrium due to a reversible oxidation-reduction system, but with an increase in concentration, the equilibrium is eliminated ${ }^{[19]}$. This example illustrates the hormetic dose-response of MB on a mitochondrial electron transport chain enzyme, a likely mechanism behind several other published studies of hormetic dose-response relationship of $\mathrm{MB}$ on various behavioral, physiological and biochemical effects that are briefly described below.

\section{MB'S HORMETIC DOSE-RESPONSE EFFECTS ON VARIOUS BEHAVIORAL MEASURES}

One of the first studies of varying MB doses on behavior examined possible memory-enhancing effects of $\mathrm{MB}$ on learned inhibitory avoidance behavior in mice and rats ${ }^{[20]}$. Inhibitory avoidance is used to evaluate memory for a simple aversive contextual conditioning, in which an animal is placed in one part of a chamber, shocked and then allowed to escape into a different part of the chamber. Latency to make the inhibitory avoidance response once an animal has been subjected to training is used as an index of the memory for the conditioning episode. This study showed that both the dose and time of $\mathrm{MB}$ administration were important for MB's memory-enhancing effect, since memory retention in an inhibitory avoidance task was improved only $24 \mathrm{~h}$ after posttraining MB injection. For example, $1 \mathrm{mg} \mathrm{kg}^{-1} \mathrm{MB}$ given intraperitoneally immediately after training sessions enhanced memory retention $24 \mathrm{~h}$ later, whereas administration either $6 \mathrm{~h}$ after training or $15 \mathrm{~min}$ before retention testing was ineffective in improving memory retention tested $24 \mathrm{~h}$ after training.

A lower dose of $0.05 \mathrm{mg} \mathrm{kg}^{-1} \mathrm{MB}$ administered immediately following the training also had a memoryenhancing effect that approached significance. Interestingly, a $5 \mathrm{mg} \mathrm{kg}^{-1} \mathrm{MB}$ dose given immediately following training did not differ from a saline-treated control condition. However, a $50 \mathrm{mg} \mathrm{kg}^{-1} \mathrm{MB}$ dose given $15 \mathrm{~min}$ before training produced amnesia in this inhibitory avoidance task, corresponding well with the principles of the hormetic dose-response relationship in which lower doses of an agent can increase a response (memory retention), until the dose is reached where there is no change in the response as compared to control and finally an even higher dose produces a response in the opposite direction (amnesia). This indicates that after low-dose MB administration there may be a compensatory response that increases over time.

A non-linear dose response to $\mathrm{MB}$ in behavioral tasks such as open field habituation, object recognition task and wheel running has also been described ${ }^{[10]}$. The first two tests assessed between-days memory retention, while the wheel running assessed general locomotor 
activity. In this study a high $\left(50 \mathrm{mg} \mathrm{kg}^{-1}\right) \mathrm{MB}$ dose resulted in decreased locomotion of animals, whereas the lower dose of $4 \mathrm{mg} \mathrm{kg}^{-1} \mathrm{MB}$ had no non-specific effects on open field activity and motivation, while it improved memory. The wheel-running response to $\mathrm{MB}$ provides another example of the behavioral hormetic dose-response effects of MB. The maximum wheelrunning response (average 142\% of control) was found at the $4 \mathrm{mg} \mathrm{kg}^{-1}$ dose, while larger doses (50 and $100 \mathrm{mg} \mathrm{kg}{ }^{-1}$ ) led to decrement below control levels (Fig. 4). In turn, $1 \mathrm{mg} \mathrm{kg}^{-1} \mathrm{MB}$, as well as $10 \mathrm{mg} \mathrm{kg}^{-1}$ MB-treated animals did not differ from saline-treated control group in the number of running wheel revolutions. Therefore, the intermediate MB dose in this study was shown to produce maximal behavioral response, with lower and higher doses having no effect and even higher doses having an opposite effect. This hormetic dose-response relationship of intraperitoneal MB injections on locomotor activity may be a result of redox state of $\mathrm{MB}$ in mitochondria enhancing or inhibiting electron transport chain enzymatic activity depending on its concentration inside the cell. At highest doses, the electrons may be taken away from cytochrome oxidase, resulting in decreased ATP production. On the other hand, an intermediate MB dose may act as an electron donor, thus driving the metabolic energy production.

In another behavioral pharmacology study, three different MB doses $(10,30$ or $100 \mathrm{nmol} / 0.5 \mu \mathrm{L})$ were injected intracranially into the dorsal periaqueductal grey of rats submitted to the elevated plus maze test ${ }^{[21]}$. The elevated plus maze test is widely used as a test of anxiety based on the natural aversion of rodents to heights and open spaces ${ }^{[22]}$. The results showed that 30 nmol MB produced the maximum response (132\% of control response) by significantly increasing the percent of time spent in the open arms of the maze and had a tendency to do the same with the percentage of open arm entries. The low and high dose of MB resulted in responses similar to control. Therefore, the MB doseresponse curve in this study had an inverted U shape, however the range of doses tested was not broad enough to observe the opposite response at a higher MB dose.

However, another study which also examined effects of various doses of $\mathrm{MB}$ on the performance of rodents in the elevated plus-maze and found similar results ${ }^{[23]}$ suggests that an opposite behavioral response could be observed in this paradigm with a higher MB dose. Importantly, in this study MB was given systemically (intravenously) over a wider range of doses. It was found that lower MB doses of $1.87 \mathrm{mg} \mathrm{kg}^{-1}$ and $3.75 \mathrm{mg} \mathrm{kg}^{-1}$ did not have an effect on the behavioral response (although there was a trend for the $3.75 \mathrm{mg} \mathrm{kg}^{-1}$ dose to increase the time spent in the open arms). Intermediate doses of $7.5 \mathrm{mg} \mathrm{kg}^{-1} \mathrm{MB}$ and $15 \mathrm{mg} \mathrm{kg}^{-1} \mathrm{MB}$ significantly increased time spent in the open arms of the maze, suggesting an anxiolytic action. On the other hand, a higher $30 \mathrm{mg} \mathrm{kg}^{-1} \mathrm{MB}$ dose had no effect on the behavioral response. Finally, the largest MB dose $\left(60 \mathrm{mg} \mathrm{kg}^{-1}\right)$ decreased the time spent in the open arms of the maze below control levels, suggesting that the high $\mathrm{MB}$ dose can be anxiogenic (the opposite response to that found with the intermediate doses). One possible confound in this study was the finding that at a $60 \mathrm{mg} \mathrm{kg}^{-1}$ dose MB also decreased the spontaneous locomotor activity, raising the question whether decrease in the time spent in the open arms of the elevated plus maze could be attributed to this more general effect. Nevertheless, it is not likely that anxiogenic properties of MB are solely due to a decrease in general activity, since no difference was found in the percent of open arm entries between subjects treated with $60 \mathrm{mg} \mathrm{kg}^{-1} \mathrm{MB}$ and control subjects.

Therefore, MB exerts a hormetic dose-response relationship on rodent behavior in the elevated plus maze, suggesting that when given within its hormetic zone range $\mathrm{MB}$ can be anxiolytic, but also indicating that too high of a dose can have an anxiogenic effect. Determining the mechanism behind these hormetic dose-response effects of $\mathrm{MB}$ on anxiolytic behavior will require more work in animal models, but one possibility is that MB-induced metabolic increases or decreases in the periaqueductal grey may contribute to dose-dependent anxiolytic and anxiogenic properties of MB.

In the same behavioral study, another behavioral paradigm, the forced swim test, was used to assess behavioral despair and antidepressant drug action after $\mathrm{MB}$ administration ${ }^{[23]}$. It was found that $\mathrm{MB}$ at $15-30$ $\mathrm{mg} \mathrm{kg}{ }^{-1}$ dose range significantly decreased the immobility time. However, the lower MB dose range (3.75-7 $\left.\mathrm{mg} \mathrm{kg}^{-1}\right)$ and higher dose $\left(60 \mathrm{mg} \mathrm{kg}{ }^{-1}\right)$ did not differ from the control condition. This suggests that a hormetic dose-response zone for MB's effect on depressive behavior in rats is between 7 and $60 \mathrm{mg}$ $\mathrm{kg}^{-1}$. It is unclear whether a higher MB dose $(>60 \mathrm{mg}$ $\mathrm{kg}^{-1}$ ) may induce change in the opposite direction and increase the behavioral despair response, since to date there are no published studies addressing this question.

\section{MB'S HORMETIC DOSE-RESPONSE EFFECTS ON VARIOUS PHYSIOLOGICAL MEASURES}

The most common current use of $\mathrm{MB}$ is for treating methemoglobinemia induced by metabolic poisons such 
as nitrates, cyanide and others. $\mathrm{MB}$ accelerates the normally slow NADP (nicotinamide adenine dinucleotide phosphate) methemoglobin reductase pathway $^{[24]}$, the mechanism by which physiologically produced methemoglobin is reduced. However, MB can also cause methemoglobinemia when administered at a higher dose ${ }^{[25]}$, due to its strong oxidizing capacity ${ }^{[26]}$ which produces equilibrium between hemoglobin and methemoglobin. Thus, MB has hormetic effects on oxygen saturation of hemoglobin, based on its concentration. At low doses, MB converts methemoglobin to hemoglobin, while at higher doses, it has the opposite effect, converting hemoglobin to methemoglobin.

Weinbroum et al. ${ }^{[27]}$ observed a non-linear MB dose-response curve in prevention of hemodynamic and metabolic derangement following the mesenteric artery clamping/unclamping, with intermediate MB doses of 6 and $20 \mathrm{mg} \mathrm{kg}^{-1} \mathrm{MB}$ producing statistically significant improvement in circulating xantine oxidase and fluid replacement requirements, while lower $\left(2 \mathrm{mg} \mathrm{kg}^{-1}\right)$ and higher $\left(60 \mathrm{mg} \mathrm{kg}^{-1}\right) \mathrm{MB}$ doses did not differ from untreated controls.

In a follow-up study ${ }^{[28]}$, it was hypothesized that MB would attenuate lung injury after mesenteric artery clamping/unclamping because of its known antioxidant properties and its effects on the nitrergic system. Interestingly, rats treated with the highest $\mathrm{MB}$ dose of $27 \mathrm{mg} \mathrm{kg}^{-1}$ did not show any significant improvement in their mean plateau pressure, while lower MB doses (3-15 $\mathrm{mg} \mathrm{kg}^{-1}$ ) improved the mean plateau pressure following the unclamping. Similarly, rats treated intravenously exhibited a facedown bell-shaped trend in fluid replacement requirements, indicating that the 27 $\mathrm{mg} \mathrm{kg}$ dose was less effective than the lower $9 \mathrm{mg}$ $\mathrm{kg}^{-1} \mathrm{MB}$ dose.

Mustafa et al. ${ }^{[29]}$ also observed better effectiveness of lower vs. higher $\mathrm{MB}$ doses in their study of vasodilation in the trout coronary system, with $\mathrm{MB}$ dose as low as $10^{\wedge}-5 \mathrm{~mol}^{-1}$ producing vasoconstriction much higher than $10^{\wedge}-2 \mathrm{~mol}^{-1}$ dose. All these studies showed that MB administered under physiological conditions in living animals does not follow a linear dose-response relationship, but rather a hormetic relationship.

\section{MB'S HORMETIC DOSE-RESPONSE EFFECTS ON VARIOUS BIOCHEMICAL VARIABLES}

In addition to the aforementioned study of MB's effects on cytochrome oxidase activity, another set of in vitro experiments found that $0.5 \mu \mathrm{M}$ concentration of MB stimulated respiration in rat liver mitochondria, but a $5 \mu \mathrm{M} \mathrm{MB}$ concentration led to structural changes in rat liver mitochondria ${ }^{[30]}$. For example, swelling is observed in mitochondria exposed to $5 \mu \mathrm{M}$, but not in mitochondria exposed to $0.5,1$, or $2 \mu \mathrm{M} \mathrm{MB}^{[30]}$. An $\mathrm{MB}$ dose of $1 \mathrm{mg} \mathrm{kg}^{-1}$ administered intraperitoneally to rats is twice as effective as $10 \mathrm{mg} \mathrm{kg}^{-1}$ in the stimulation of liver mitochondrial metabolism in vivo ${ }^{[30]}$. Large doses of $\mathrm{MB}$, such as $50-100 \mathrm{mg} \mathrm{kg}^{-1}$, are detrimental because they lead to methemoglobin formation and memory deficits in mice and rats ${ }^{[10,20]}$

As an electron donor, MB has been shown to be able to shunt electron flow in electron transport chain enzymes such as complex I and cytochrome oxidase from the normal pathway to the iron-sulfur centers instead, thus eventually generating reactive oxygen. However, 1-25 $\mathrm{mg} \mathrm{mL}^{-1} \mathrm{MB}$ can also act as an antioxidant, suggesting that depending on the range of concentrations used $\mathrm{MB}$ can either donate or accept electrons $^{[31]}$. Thus, as an electron donating or accepting chemical substance, MB does not have a pharmacological dose-response profile in which increasing concentrations exert a linear increase of biochemical responses. Rather, careful examination of range of concentrations is important when working with artificial electron donors such as MB, because the primary site of removal of electrons from the electron transport chain and the proportion returned to the electron transport chain in the mitochondria are dependent on the concentrations used. Furthermore, very low concentrations of MB should be used in order to create a successful bypass of a part of the electron transport chain and still retain intact phosphorylation mechanisms in other parts ${ }^{[32]}$.

In addition to its redox properties, $\mathrm{MB}$ is also a known soluble guanylate cyclase inhibitor and direct inhibitor of nitric oxide synthase, as well as monoamine oxidase inhibitor (MAO-A and MAO-B), thus potentially affecting both the nitrergic system and serotonergic neurotransmission ${ }^{[33]}$. However, $\mathrm{MB}$ is a poor inhibitor of the nitrergic system at low concentrations $^{[34]}$ that produce MB's maximal pharmacological responses described above. Additionally, at high concentration $(0.5 \mathrm{mM}) \mathrm{MB}$ may be considered as a cholinesterase inhibitor with relevant affinity for muscarinic binding sites ${ }^{[35]}$. In a study which investigated substrate binding to muscarinic receptors, as well as esterase activity of human and bovine plasma, $\mathrm{MB}$ was found to inhibit specific binding of radiolabeled substrate to muscarinic receptors and to inhibit esterase activity ${ }^{[35]}$. At even higher concentrations (10-25 mM), MB can increase ATPase activity in vitro ${ }^{[36]}$. In addition, recent in vitro studies using high MB concentrations indicate that it can prevent the aggregation of tau filaments and amyloid deposition characteristic of Alzheimer's 
brains $^{[37-39]}$. This is an intriguing finding that requires further studies, especially in view of the MB studies with demented patients done in the 1930 ' $\mathrm{s}^{[2]}$ before the development of $\mathrm{MB}$ derivatives such as the phenothiazine neuroleptics. Thus, further work will be necessary to fully evaluate how different MB doses exert their effect at the systems level in the in vivo studies and how interactions between various substrates of $\mathrm{MB}$ contribute to its hormetic dose-response relationships in the various behavioral, physiological and biochemical responses described above.

In conclusion, the studies reviewed provide support for classifying $\mathrm{MB}$ as an autoxidizable compound frequently characterized by hormetic dose-response relationships at behavioral, physiological and biochemical levels. Thus, at the doses spanning its hormetic zone, MB can increase these responses until they are $130-160 \%$ of control. For example, low doses of $\mathrm{MB}$ produce a maximum behavioral response with averages of approximately $140 \%$ of control ${ }^{[10,20]}$. However, as MB dose is increased the response level diminishes, until it returns to control baseline response. After MB dose is raised outside the hormetic zone for MB (average 10-20 fold) then the response decreases below the control response, as exemplified by MB's ability to increase cytochrome oxidase activity at low doses, while decreasing cytochrome oxidase activity at high doses. The autoxidizable electron cycling property of $\mathrm{MB}$ in the electron transport chain in mitochondria may account for its unique combination of actions as metabolic energy enhancer and antioxidant so that pharmacological responses to $\mathrm{MB}$ are often characterized by nonlinear dose-response curves, where at low doses the response is opposite to that of higher doses, while the intermediate doses have little or no effect on the response variable. However, further work is needed to understand how this key biochemical property of MB may be related to its other actions.

\section{ACKNOWLEDGMENTS}

This study was supported by NIH grants MH65728 and $\mathrm{MH} 076847$.

\section{REFERENCES}

1. Wainwright, M. and K.B. Crossley, 2002. Methylene Blue-a therapeutic dye for all seasons? J. Chemother., 14: 431-443.

2. Allexsaht, W.J., 1938. The use of methylene blue in the treatment of catatonic dementia praecox patients. Psychiatric Q., 12: 245-252.
3. Naylor, G.J. et al., 1986. A two-year double-blind crossover trial of the prophylactic effect of methylene blue in manic-depressive psychosis. Biol. Psychiatry, 21: 915-920.

4. Deutsch, S. et al., 1997. Methylene blue adjuvant therapy of schizophrenia. Clin. Neurupharmacol., 20: 357-363.

5. Pelgrims, J. et al. 2000. Methylene blue in the treatment and prevention of ifosfamide-induced encephalopathy: Report of 12 cases and a review of the literature. Br. J. Cancer, 82: 291-294.

6. Clifton, J. and J. Leikin, 2003. Methylene blue. Am. J. Therapeutics, 10: 289-291.

7. Kelner, M. et al., 1988. Potential of methylene blue to block oxygen radical generation in reperfusion injury. Basic Life Sci., 49: 895-898.

8. Callaway, N.L. et al., 2004. Methylene blue improves brain oxidative metabolism and memory retention in rats. Pharmacol. Biochem. Behav., 77: $175-181$.

9. Callaway, N.L. et al., 2002. Methylene blue restores spatial memory retention impaired by an inhibitor of cytochrome oxidase in rats. Neurosci. Lett., 332: 83-86.

10. Riha, P.D. et al., 2005. Memory facilitation by methylene blue: Dose-dependent effect on behavior and brain oxygen consumption. Eur. J. Pharmacol., 511: 151-158.

11. Gonzalez-Lima, F. and A.K. Bruchey, 2004. Extinction memory improvement by the metabolic enhancer methylene blue. Learning \& Memory, 2004. 11(5): 633-640.

12. Zhang, X., J. Rojas and F. Gonzalez-Lima, Methylene blue prevents neurodegeneration caused by rotenone in the retina. Neurotoxicity Res., 9: 47-57.

13. Calabrese, E.J. et al., 2007. Biological stress response terminology: Integrating the concepts of adaptive response and preconditioning stress within a hormetic dose-response framework. Toxicol. Applied Pharmacol., 222: 122-128.

14. Clark, W.M., B. Cohen and H.D. Gibbs, 1925. Studies on oxidation-reduction VIIII-Methylene blue. US Pub Health Rep, 40: 1131-1201.

15. Bongard, R.D. et al., 1995. Reduction of thiazine dyes by bovine pulmonary arterial endothelial cells in culture. Am. J. Physiol., 269: L78-84.

16. May, J.M., Z.C. Qu and C.E. Cobb, 2004. Reduction and uptake of methylene blue by human erythrocytes. Am. J. Physiol. Cell Physiol., 286: C1390-1398. 
17. Atamna, H. et al., 2007. Methylene blue delays cellular senescence and enhances key mitochondrial biochemical pathways. FASEB J.,22: 703-712.

18. Wong-Riley, M., 1989. Cytochrome oxidase: An endogenous metabolic marker for neuronal activity. Trends Neurosci., 12: 94-101.

19. Cragan, J., 1999. Teratogen update: Methylene blue. Teratology, 60: 42-48.

20. Martinez Jr., J.L., et al. 1978. Methylene blue alters retention of inhibitory avoidance responses. Physiological Psychol., 6: 387-390.

21. De Oliveira, R.W. and F.S. Guimaraes, 1999. Anxiolytic effect of methylene blue microinjected into the dorsal periaqueductal gray matter. Brazilian J. Medical Biol. Res., 32: 1529-1532.

22. Dawson, G.R. and M.D. Tricklebank, 1995. Use of the elevated plus maze in the search for novel anxiolytic agents. Trends Pharmacol. Sci., 16: 33-36.

23. Eroglu, L. and B. Caglayan, 1997. Anxiolytic and antidepressant properties of methylene blue in animal models. Pharmacol. Res., 36: 381-385.

24. Yusim, Y., D. Livingstone and A. Sidi, 2007. Blue dyes, blue people: the systemic effects of blue dyes when administered via different routes. J. Clin. Anesthesia, 19: 315-321.

25. Burrows, G.E., 1984. Methylene blue: Effects and disposition in sheep. J. Vet. Pharmacol. Ther., 7: 225-231.

26. Young, D., L. Pestaner and V. Gibberman, 1975. Effects of drugs on clinical laboratory tests. Clin. Chem., 21: 1D-432D.

27. Weinbroum, A.A. et al., 2002. Methylene blue in preventing hemodynamic and metabolic derangement following superior mesenteric artery clamping/unclamping: An intrathecal vs. intraperitoneal dose-response study. Shock, 17: 372-376.

28. Weinbroum, A.A., 2004. Methylene blue attenuates lung injury after mesenteric artery clamping/unclamping. Eur. J. Clin. Invest., 34: 436-442.

29. Mustafa, T., C. Agnisola and J. Hansen, 1997. Evidence for NO-dependent vasodilation in the trout (Oncorhynchus mykiss) coronary system. J. Comp. Physiol. B: Biochem. Syst. Environ. Physiol., 167: 1432-1436.
30. Visarius, T.M., J.W. Stucki and B.H. Lauterburg, 1997. Stimulation of respiration by methylene blue in rat liver mitochondria. FEBS Lett., 412: $157-160$.

31. Salaris, S.C., C.F. Babbs and W.D. Voorhees III, 1991. Methylene blue as an inhibitor of superoxide generation by xanthine oxidase. Biochem. Pharmac., 42: 499-506.

32. Scott, A. and F.E. Hunter Jr., 1966. Support of thyroxine-induced swelling of liver mitochondria by generation of high energy intermediates at any one of three sites in electron transport chain. J. Biol. Chem., 241: 1060-1066.

33. Ramsay, R.R., C. Dunford and P.K. Gillman, 2007. Methylene blue and serotonin toxicity: inhibition of monoamine oxidase A (MAO A) confirms a theoretical prediction. Br. J. Pharmacol., 152: 946951.

34. Mayer, B., F. Brunner and K. Schmidt, 1993. Novel actions of methylene blue. Eur. Heart J., 14: 22-26.

35. Pfaffendorf, M. et al., 1997. The interaction between methylene blue and the cholinergic system. Br. J. Pharmacol., 122: 95-98.

36. Shah, D.I., D.D. Santani and S.S. Goswami, 2006. A novel use of methylene blue as a pharmacological tool. J. Pharmacol. Toxicol. Methods, 54; 273-277.

37. Wischik, C.M. et al., 1996. Selective inhibition of Alzheimer disease-like tau aggregation by phenothiazines. Proc. Natl. Acad. Sci., 93: 11213-11218.

38. Taniguchi, S. et al., 2005. Inhibition of heparininduced tau filament formation by phenothiazines, polyphenols and porphyrins. J. Biol. Chem., 280: 7614-7623.

39. Necula, M. et al., 2007. Methylene blue inhibits amyloid beta oligomerization by promoting fibrillization. Biochemistry, 46: 8850-8860. 